Rev. Adm. Saúde - Vol. 18, № 70, jan. - mar. 2018

http://dx.doi.org/10.23973/ras.70.80

ARTIGO ORIGINAL

\title{
Análise do gasto médio por internação em hospitais de Mato Grosso: a gestão por OSS em foco
}

Analysis of average medical expenditure by hospital in Mato Grosso: OSS management in focus

\section{Paulo Cesar Souza1, João Henrique Gurtler Scatena², Ruth Terezinha Kehrig $^{3}$}

1. Bacharel em ciências contábeis, doutor em ciências da saúde. Professor da Universidade do Estado de Mato Grosso (UNEMAT). Contador da Secretaria de Estado de Saúde do Estado de Mato Grosso (SES/MT)

2. Médico, doutor em saúde pública. Professor do Instituto de Saúde Coletiva (ISC) da Universidade Federal de Mato Grosso (UFMT)

3. Bacharel em administração, doutora em saúde pública. Professora do Instituto de Saúde Coletiva (ISC) da Universidade Federal de Mato Grosso (UFMT)

\section{RESUMO}

$\mathrm{Na}$ busca por modelos gerenciais que superem a rigidez da administração burocrática tradicional, tem sido adotada a transferência de gestão de hospitais públicos para organizações sociais de saúde (OSS). Diante dessa realidade, este trabalho se propôs a analisar o gasto médio por internação em oito hospitais de Mato Grosso, comparando os valores da gestão por OSS com outros arranjos organizacionais utilizados no estado, e com valores oriundos de estudos assemelhados. A comparação indicou um valor bastante elevado de gasto, acima dos daqueles encontrados em outras formas de gestão e mesmo em hospitais que também têm gestão por OSS, de outro estado (SP). Os dados suscitam a necessidade de melhor acompanhamento da operacionalização desse modelo, em MT, principalmente quanto aos gastos para manutenção.

Palavras-chave: Sistema Único de Saúde, administração hospitalar, economia da saúde 


\section{ABSTRACT}

In the search for management models that overcome the rigidity of traditional bureaucratic administration, has been adopted to transfer public hospitals management for health social organizations (OSS). Given this reality, this study aimed to analyze the average expenditure per hospitalization in eight Mato Grosso hospitals thick, comparing the OSS by management values with other organizational arrangements used in the state, and with values derived from the like studies. The comparison indicated a fairly high value expenditure, above those found in other forms of management and even in hospitals that also have management by OSS, of another state (SP). The data raise the need for better monitoring of the implementation of this model in MT, mainly as the expenses for maintenance.

Keywords: unified health system, hospital administration, health economics.

\section{INTRODUÇÃO}

Os hospitais são organizações que, pela sua própria natureza são complexas, tornando sua gestão um grande desafio. Na busca por modelos gerenciais e formatos jurídicos que contemplem as peculiaridades desse tipo de organização, surgiram os diversos arranjos organizacionais existentes no Brasil. Tais arranjos são definidos como características específicas do ambiente hospitalar que influenciam o comportamento da instituição e também seu desempenho'.

Os diversos arranjos organizacionais têm implicações na propriedade do patrimônio e nas normas administrativas para o funcionamento da organização e podem ser agrupados em três grandes conjuntos ${ }^{2}$ : o primeiro é de caráter público e estatal e integra a administração pública. O segundo é constituído no âmbito privado, mas desempenha funções de interesse público. Os componentes desse grupo integram o chamado "terceiro setor", prestando seus serviços à administração em conformidade com as condições estabelecidas em lei. O terceiro grupo também é de natureza privada e atua com base nas regras de mercado, podendo, mediante contrato, prestar serviços à administração pública.

Essa categorização dos arranjos existentes no Brasil é semelhante aos arranjos existentes nos países europeus. Analisando o sistema de saúde dos países europeus, Saltman ${ }^{3}$ identificou quatro categorias com base no formato jurídico-administrativo das instituições: o público estatal, o público não estatal, o privado com fins de lucro e o privado não lucrativo.

A necessidade de uma reestruturação no modelo administrativo do Estado a fim de alcançar melhoria na eficiência fomentou a implementação do Plano 
Diretor de Reforma do Aparelho do Estado (PDRAE), proposto pelo Ministério da Administração e Reforma do Estado (MARE) do governo FHC (1995-2002). O ponto de destaque desse plano não é o grau de consenso alcançado, mas, sobretudo, o fato de representar uma intervenção concreta sobre o problema colocado, redefinindo as relações entre Estado e Sociedade 4 .

Sendo conduzida pelo Ministro Bresser Pereira, o Plano Diretor de Reforma do Aparelho do Estado teve como estratégia central a implementação das Organizações Sociais. O propósito seria permitir e incentivar a publicização, ou seja, que bens e serviços não exclusivos de Estado fossem produzidos pela sociedade. A absorção de atividades pelo terceiro setor tem sido uma marca das reformas de estado realizadas nas democracias contemporâneas ${ }^{5}$.

Acompanhado essa onda de reformas, o estado de São Paulo iniciou, em 1998 o processo de implantação do modelo de gestão baseado nas Organizações Sociais nos serviços de saúde. Outros estados como Ceará, Minas Gerais e Rio de Janeiro promoveram reformas adotando também o mesmo arranjo ${ }^{6,1}$. A partir de 2011, o estado de Mato Grosso vem passando pelo mesmo processo, transferindo a gestão dos hospitais públicos regionais para as OSS.

Diante dessa nova realidade no estado de Mato Grosso, e da necessidade de produzir conhecimento a respeito da operacionalização do modelo, este trabalho se propôs a analisar e comparar os gastos de dois desses hospitais com os de outros arranjos empregados no estado e com resultados de estudos assemelhados realizados no estado de São Paulo.

\section{Arranjos organizacionais nos hospitais públicos do Brasil}

Os arranjos organizacionais existentes no setor público brasileiro tiveram origem em três ondas de reformas ${ }^{1}: 1$ ) a reforma administrativa estabelecida pelo Decreto-Lei 200 de 1967, que criou a figura da administração indireta; 2) a promulgação da Constituição Federal de 1988 e as legislações que vieram a seguir e criaram o regime jurídico único para os servidores públicos (Lei 8.112/1990), as licitações (Lei 8.666/93) e a descentralização dos serviços de saúde (Lei 8.080/1990). Esta segunda onda de reformas trouxe grandes restrições à autonomia das instituições públicas da administração indireta; 3) reformas realizadas no fim dos anos 90 (EC 19/1998), criando os modelos organizacionais autônomos como as organizações sociais.

O regime jurídico em que os hospitais públicos se enquadram ou atuam também é uma das formas de se apreender os arranjos organizacionais dessas unidades. As possibilidades de classificação e as principais características de cada um deles são apresentadas a seguir $7,8,9,10$.

a - Regime jurídico de direito público

a.1 - Administração direta: os serviços são prestados pelo próprio poder público através de seus órgãos e sob sua exclusiva responsabilidade. 
Essa denominação "administração direta" foi dada pelo Decreto-lei 200/67. O Estado atua diretamente podendo ser sob a forma de desconcentração, sem o surgimento de outro ente. A organização assistencial prestadora de serviços não possui personalidade jurídica própria, estando subordinada ao regime administrativo. É um modelo pouco apropriado para a execução de serviços públicos, principalmente em virtude da falta de autonomia administrativa, orçamentária e financeira.

a.2 - Administração indireta: a "administração indireta", denominação dada pelo Decreto-lei 200/67 é também chamada de administração descentralizada. Nessa modalidade, a atividade do Estado é exercida indiretamente através de pessoas juridicamente distintas, ainda que tais pessoas tenham sido criadas pelo próprio Estado. Tais pessoas jurídicas gozam de certa autonomia, a qual é definida em sua lei de criação.

a.2.1 - Autarquia: são pessoas jurídicas de direito público criadas por lei, dotadas de patrimônio próprio, a fim de executar atividade administrativa típica do Estado. É um tipo de descentralização administrativa, sendo que gozam de liberdade administrativa nos limites da lei que a criou, não sendo subordinadas ao órgão de Estado, mas apenas controladas por ele. O regime dos servidores é o mesmo da administração direta e a autarquia está sujeita ao cumprimento da legislação aplicada à administração pública, assim como à fiscalização pelo Tribunal de Contas.

a.2.1.1 - Autarquia de regime especial: são aquelas autarquias às quais a lei de criação conferiu privilégios especiais e aumentou sua autonomia, em comparação com as autarquias comuns, dentro dos limites constitucionais aplicáveis a esse tipo de entidade da administração indireta. Os principais exemplos são: Banco Central do Brasil, Comissão Nacional de Energia Nuclear, Universidade de São Paulo, e as entidades responsáveis pela fiscalização das profissões regulamentadas, ou seja, CRE, OAB, CRC, etc.

a.2.1.2 - Agência executiva: Uma agência executiva não é uma nova modalidade de administração indireta, mas um título que pode ser atribuído à autarquia ou fundação. Essa denominação surgiu com o advento da Lei 9.649/98 e foi disciplinada pelos Decretos 2.487/98 e $2.488 / 98$. No âmbito do governo federal esse título é concedido pelo Presidente da República, estabelecendo condições especiais de operação para as autarquias e fundações que cumprirem os seguintes requisitos: i) tenham celebrado contrato de gestão com o ministério supervisor; ii) tenham um plano estratégico de reestruturação e desenvolvimento institucional voltado para a melhoria da gestão e redução de custos. Um dos benefícios concedidos às agências executivas é a ampliação do limite de dispensa de licitação para o dobro do limite estabelecido pela Lei de Licitações e Contratos (8.666/93). Ressalta-se que esse tipo de agência pode ser instituída também nos demais níveis de governo, devendo cada um criar sua própria lei regulamentadora. Não existem muitas organizações da administração 
indireta que possuam tal qualificação, podendo ser citadas atualmente o Instituto Nacional de Metrologia e Qualidade Industrial (INMETRO), Agência Brasileira de Inteligência (ABIN) e ainda a Superintendência de Desenvolvimento da Amazônia (SUDAM) e a Superintendência de Desenvolvimento do Nordeste (SUDENE).

a.2.1.3 - Agência reguladora: em sentido amplo seria, no âmbito do direito brasileiro, qualquer órgão da administração direta ou indireta que tenha a função de regular, fiscalizar a matéria que lhe for específica e atribuída por lei. Com a iniciativa do governo de transferir alguns serviços públicos para a iniciativa privada, cabe ao governo regular, fiscalizar e controlar tais serviços a fim de defender os direitos dos usuários e da sociedade. Para realizar essa atividade foram criadas as agências reguladoras. Existem várias no país, dentre as quais é possível citar: ANATEL, ANEEL, ANA, ANS, ANVISA etc.

a.2.2 - Fundação de direito público: São entidades criadas para realizar atividades não lucrativas e que não são típicas do poder público, mas de interesse coletivo como educação, cultura e pesquisa. Foram criadas inicialmente como entidades de direito privado, no entanto, a partir da adoção por parte do governo da figura da fundação para atender objetivos de interesse público, passou-se a atribuir a essas entidades personalidade pública. Assim, a Constituição Federal de 1988 transformou a fundação pública num tipo de autarquia, ou seja, embora com nomenclatura diferente submete-se às mesmas normas das autarquias. Assim, sua constituição deve ser a partir de lei específica, os contratos devem ser precedidos de licitação e o orçamento é formalmente idêntico ao das entidades estatais, estando também sujeita à fiscalização do Tribunal de Contas. Exemplos: hemocentros e algumas universidades federais.

\section{a.2.3 - Consórcio público: São pessoas jurídicas dotadas de} personalidade pública ou privada, criadas mediante autorização legislativa dos diversos entes envolvidos para a execução de serviços públicos que sejam de interesse comum dos consorciados. O objetivo é reunir recursos financeiros, técnicos e administrativos, que cada um individualmente não teria para executar a referida atividade. É bastante comum na área da saúde, podendo ser utilizado para gerenciar um hospital regional ou região de saúde. Na área de saúde o primeiro a ser criado foi em Penápolis - SP, no ano de 1986. Em Mato Grosso foi o Consórcio Teles Pires, em 1995, composto inicialmente por sete, e atualmente por quinze municípios da região centro norte do estado ${ }^{11}$.

\section{b - Regime jurídico de direito privado}

b.1 - Fundação pública de direito privado: A Emenda Constitucional 19/98 trouxe nova redação ao inciso XIX do artigo 37 da Constituição Federal, aludindo ao entendimento anterior de que a fundação é entidade com personalidade jurídica de direito privado. Sua criação 
deverá ser autorizada por lei complementar, a qual deverá definir suas áreas de atuação. Tem como características principais: controle do Tribunal de Contas, empregados considerados empregados públicos, escolha pública para contratação de pessoal, no entanto, regidos pela CLT, compra e contratos por licitação mediante pregão e consulta pública, não está sujeita aos limites de despesa impostos pela LRF, contrato de gestão, autonomia administrativa, orçamentária e financeira. Está em tramitação na Câmara Federal o projeto de Lei Complementar 92/07 que regulamenta a criação das fundações estatais de direito privado estabelecendo como uma das áreas de atuação a saúde.

b.2 - Empresa pública: Entidade de personalidade jurídica de direito privado, criada mediante autorização legal a fim de explorar atividade econômica em igualdade de condições com as empresas privadas. $\mathrm{O}$ principal exemplo no país é a Caixa Econômica Federal. Existe também um hospital que opera no país com esse regime desde 1970, pertencente à Universidade Federal do Rio Grande do Sul.

b.3 - Sociedade de economia mista: São pessoas jurídicas de direito privado constituídas sob a forma de Sociedade Anônima, com participação do poder público e de particulares em seu capital e na sua administração a fim de executar atividade econômica ou serviço público outorgado pelo estado. Admite-se lucro e regem-se pelas normas mercantis, podendo ter adaptações impostas pela lei que autoriza a criação e o funcionamento. Os principais exemplos são a Petrobrás e o Banco do Brasil. Existe no Rio Grande do Sul o Grupo Hospitalar Conceição, composto por cinco hospitais e cerca de 1.800 leitos, que opera sob esse regime jurídico.

b.4 - Entidades paraestatais: São pessoas jurídicas de direito privado que atuam paralelamente ao Estado, executando atividades de interesse do Estado, mas não privativas.

b.4.1 - Serviços sociais autônomos: São entidades com personalidade jurídica de direito privado criadas por lei a fim de prestar assistência ou ensino a certas categorias ou grupos profissionais, sem fins lucrativos e recebendo proteção do Estado e beneficiando-se de seu poder, inclusive o tributário. Os mais comuns são os serviços ligados à indústria e ao comércio SESI, SESC e SENAI. O Hospital das Pioneiras Sociais é uma rede de hospitais que se estende por cinco estados e que se utiliza desse regime jurídico.

b.4.2 - Organizações sociais (OSS): São entidades com personalidade jurídica de direito privado oriundas da lei 9.637/98, sem fins lucrativos, qualificadas como de interesse social pelo poder executivo para executar atividades voltadas para o ensino, pesquisa, desenvolvimento tecnológico, preservação do meio ambiente, cultura e saúde. Tais organizações podem executar serviços públicos mediante contrato de gestão. As principais características das organizações sociais são: autonomia de gestão; sem finalidade lucrativa, devendo o excedente ser reaplicado em sua atividade; possui órgãos diretivos colegiados com 
participação do governo e da comunidade; contratação de pessoal sob o regime celetista (CLT) sem concurso público; celebração de contrato com o poder público com a fixação de metas e controle de resultados; privilégios tributários. Na área de saúde, o estado de São Paulo foi o pioneiro na adoção do modelo para a gestão de hospitais.

b.4.3 - Organização da Sociedade Civil de Interesse Público (OSCIP): São entidades de personalidade jurídica de direito privado não submetidas às regras do direito público, disciplinadas pela lei 9.790/99, criadas por particulares e qualificadas pelo poder executivo como tal. São semelhantes às organizações sociais tendo como principal diferença o fato da organização social poder receber delegação para a gestão de serviço público, enquanto a OSCIP exerce atividade de natureza privada, recebendo para isso auxílio do estado.

b.4.4 - Entidades de apoio: são pessoas jurídicas de direito privado, sem fins lucrativos, constituídas por servidores públicos, em nome próprio, sob a forma de fundação, associação ou cooperativa a fim de prestar serviços sociais não exclusivos do Estado, mantendo vínculo jurídico com entidades da administração direta por meio de convênio. Apresenta as seguintes características: não são instituídas pelo poder público, mas por servidores; a forma mais comumente utilizada é a fundação, inserindo em seus estatutos objetivos iguais aos da entidade pública junto a qual pretende atuar; atua mais comumente junto a hospitais públicos e universidades públicas; não está sujeita ao regime jurídico público, tendo empregados celetistas sem concurso e compras sem licitação. Na área da saúde a mais conhecida é a Fundação Zerbini que apoia o Instituto do Coração - INCOR.

As diversas possibilidades de arranjos organizacionais conformados nos hospitais públicos do Brasil ao longo da história, embora tenham surgido em períodos diferentes, tinham sempre como objetivo contornar a rigidez da administração direta e proporcionar flexibilidade e autoridade para os gestores ${ }^{1}$.

Mesmo diante da criação da figura da administração indireta pelo Decreto-Lei 200/67, "os modelos da administração direta, autárquica e mesmo de fundação pública restringem a autonomia aos dirigentes hospitalares nos mais diversos âmbitos administrativos" ${ }^{2}$. Segundo esses autores, tal limitação de autonomia permanece porque estão submetidos às diversas legislações do setor público relacionas à área de pessoal, compras e orçamento.

\section{METODOLOGIA}

Este trabalho é um recorte de uma tese de doutorado em ciências da saúde (UFMT), defendida no ano de 2014, e caracteriza-se como um estudo 
multicaso descritivo, com abordagem quantitativa, realizado em oito hospitais de diferentes naturezas jurídicas.

$\mathrm{Na}$ tese, foram analisados 10 hospitais, no entanto, para este recorte, dois hospitais não dispunham dos dados necessários, de modo que restaram oito.

Os hospitais selecionados estão localizados em três regiões do estado, as quais estão entre as cinco regiões com maior concentração populacional. Para a seleção dos hospitais foi utilizado o seguinte critério: considerar distintos tipos de prestador; tentou-se, sempre que possível, incluir um hospital público, um privado e um filantrópico de cada região. Foram escolhidos os hospitais privados e filantrópicos que possuem o maior número de leitos disponíveis para pacientes SUS. Os hospitais privados e filantrópicos, existentes nessas regiões, que não disponibilizam leitos para atendimento SUS foram automaticamente excluídos.

Quanto ao porte, os hospitais deveriam possuir no mínimo 30 leitos. Além disso, os hospitais privados e filantrópicos deveriam ter pelo menos $50 \%$ de seus leitos disponíveis para atendimento SUS.

A Tabela 1 mostra que dentre estes, três são filantrópicos, dois privados e três públicos. Quanto ao total de leitos gerais, os hospitais somam 625, sendo 296 (32\%) filantrópicos, 117 (18\%) privados e 212 (33,9\%) públicos.

Quanto aos leitos disponíveis para o SUS, os quais fizeram parte desta pesquisa, eles totalizam 518 , ou seja, $82,8 \%$ do total de leitos dos hospitais selecionados. São 213 leitos (41\%) localizados em hospitais filantrópicos, 93 leitos (17,9\%) em hospitais privados e 212 leitos (40,9\%) em hospitais públicos. A fim de manter o anonimato, os hospitais foram identificados por número nos resultados.

Tabela 1. Hospitais objeto da pesquisa segundo natureza jurídica e leitos, Mato Grosso, 2011.

\begin{tabular}{l|llrr}
\hline Região & Hospital & $\begin{array}{l}\text { Natureza } \\
\text { Jurídica }\end{array}$ & $\begin{array}{r}\text { Leitos } \\
\text { Totais }\end{array}$ & $\begin{array}{r}\text { Leitos } \\
\text { SUS }\end{array}$ \\
\hline B. Cuiabana & Hospital Geral Universitário & Filantrópico & 159 & 101 \\
Tangará Serra & Hosp. e Matern. Renato Sucupira & Filantrópico & 49 & 40 \\
Cáceres & Hospital São Luiz & Filantrópico & 88 & 72 \\
\hline & Total Filantrópico (3) & & 296 & 213 \\
\hline B. Cuiabana & Hospital e Maternidade Santa Rita & Privado & 87 & 63 \\
Tang. da Serra & Centro Hospitalar Parecis & Privado & 30 & 30 \\
\hline & Total Privado (2) & & 117 & 93 \\
\hline Tangará Serra & Hospital Mun. de Barra do Bugres & Público & 78 & 78 \\
Cáceres & Hospital Regional de Cáceres & Público & 82 & 82 \\
B. Cuiabana & Hosp. Metrop. de Várzea Grande & Público & 52 & 52 \\
\hline & Total Público (3) & & 212 & 212 \\
\hline
\end{tabular}




\begin{tabular}{l|lll}
\hline & Total Geral (8) & 625 & 518 \\
\hline Fonte: CNES
\end{tabular}

Os dados para a análise do gasto médio por internação foram obtidos junto aos hospitais mediante visita e autorização prévia de seus diretores e são referentes ao primeiro semestre de 2012. Os dados referentes às internações (quantidade e valores) foram obtidos junto aos hospitais e no SIH/SUS, disponível no DATASUS ${ }^{12}$. Tais dados foram tabulados utilizando o Epidata 3.1.

O indicador gasto médio por internação foi escolhido diante da dificuldade de se obter informação sobre custos, o que seria o ideal, no entanto, a maioria dos hospitais não realiza uma apuração sistemática de custos. Assim, esse indicador mostra de forma aproximada, em média, quanto o hospital gastou para realizar cada internação. Um estudo realizado por Ferreira ${ }^{19}$ para analisar a eficiência hospitalar utilizou o mesmo indicador. $\mathrm{O}$ indicador receita média $\mathrm{SIH}$ foi escolhido a fim de demonstrar, em média, quanto o hospital recebe do SUS por cada internação, possibilitando a comparação entre os valores.

Os dados de gasto médio e de faturamento SUS foram processados utilizando o Microsoft Excel e analisados tendo como foco sua comparação tendo em vista a tipologia dos oito hospitais: público com administração direta, público com gestão por OSS, filantrópico e privado.

A pesquisa foi submetida ao Comitê de Ética em Pesquisa, recebendo parecer favorável sob número 45.667 de 27/06/2012 e os procedimentos realizados obedeceram aos termos do documento de autorização da pesquisa emitido pela direção de cada hospital.

\section{RESULTADOS E DISCUSSÃO}

A Figura 1 apresenta uma comparação entre os valores médios da receita de faturamento SIH/SUS por internação e gasto médio por internação para manutenção do hospital no período compreendido entre janeiro e junho de 2012.

Como é possível notar, há uma grande diferença entre o valor médio recebido por internação SIH/SUS e o gasto médio por internação para a manutenção do hospital. Aparece como única exceção o hospital 10, onde, por perda de dados por parte do hospital, o valor para manutenção está subdemonstrado. Como já destacado, o grupo de hospitais selecionados é heterogêneo, contemplando hospitais de diversos portes e complexidade, o que explica a grande diferença principalmente entre os valores médios das despesas para manutenção dos oito hospitais, variando de $R \$ 550,69$ a $R \$ 11.136,56$.

Chamam a atenção os hospitais que apresentaram os maiores valores médios de gasto para manutenção por internação, os quais por ordem decrescente 
são: hospital $1(11.136,56)$, hospital $3(10.951,30)$, e hospital $6(5.646,06)$. Dois fatores poderiam explicar a magnitude dos valores: o porte e a complexidade.

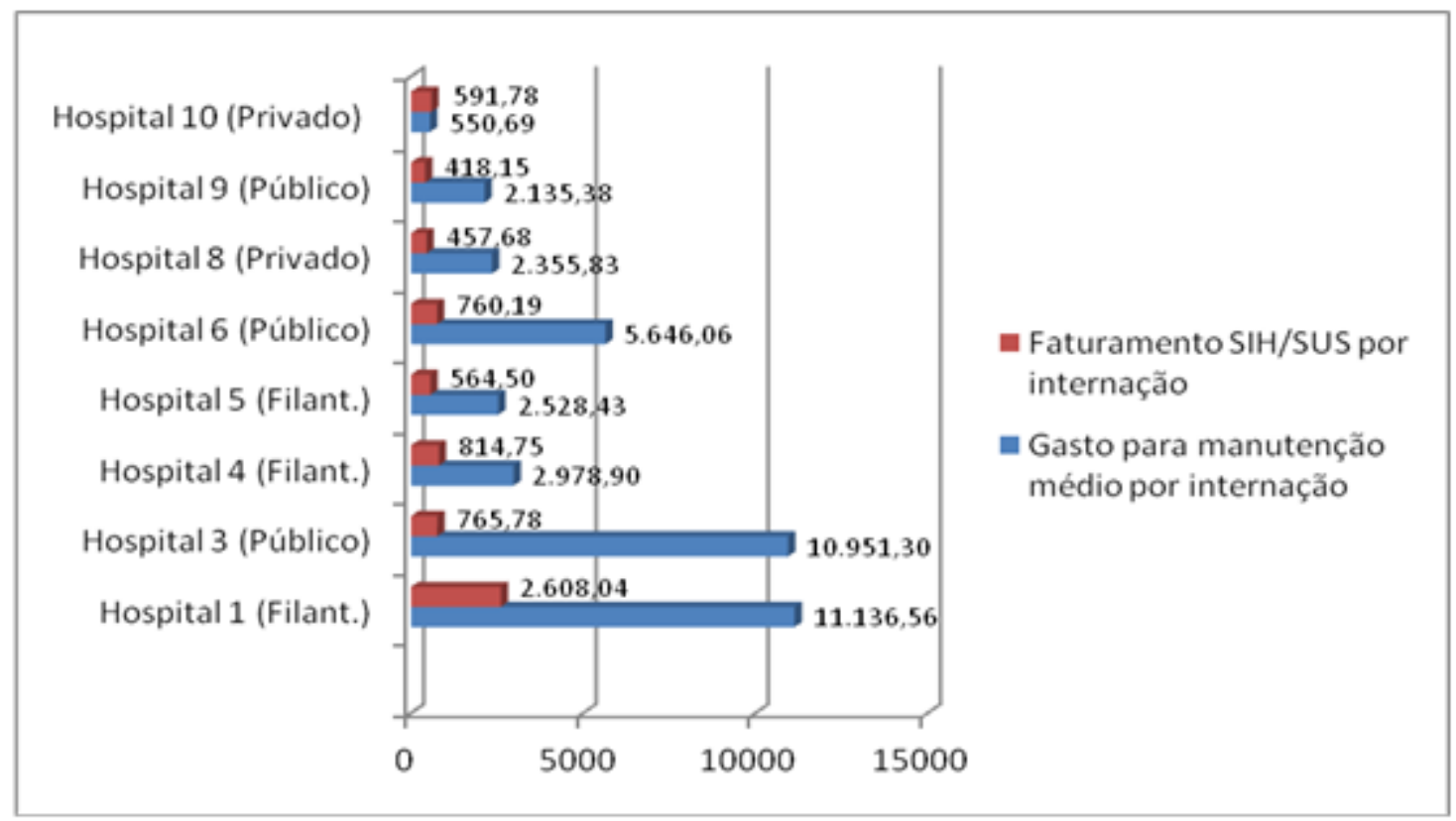

Figura 1. Comparativo entre valor médio de receita SIH por internação SUS e gasto para manutenção do hospital médio por internação total, segundo a natureza jurídica, Mato Grosso, 2012.

Quanto ao porte, se considerados apenas os leitos SUS, os três hospitais são de médio porte. Ao considerar os leitos totais, um deles passa a pertencer ao grupo dos hospitais de grande porte por exceder em nove leitos o limite de classificação para médio porte ${ }^{13}$, sendo este o que apresentou o maior valor de gasto médio para manutenção.

Quanto à complexidade, a análise dos valores médios do faturamento SIH/SUS indica que o hospital 1 tem um nível mais elevado de complexidade, informação confirmada ao analisar os dados coletados. Entre os dados coletados na pesquisa, os hospitais informaram o número de internações totais e o número de internações ou procedimentos de alta complexidade na internação. Conforme esses dados, no hospital 1 as internações/procedimentos de alta complexidade representaram $27 \%$ das internações totais enquanto no hospital 3 representaram $5 \%$ e no hospital 6 apenas $1 \%$.

Assim, ao comparar os três hospitais que apresentaram os maiores valores médios de gastos para manutenção, apenas no hospital 1 os valores parecem ser compatíveis com o porte e a complexidade, pois o mesmo é de grande porte (leitos totais) e realizou grande número de internações/procedimentos de alta complexidade no período. A mesma afirmativa não pode ser feita em relação aos hospitais 3 e 6 que apresentam valores aparentemente incompatíveis com o porte e a complexidade, com o agravante do hospital 3 
apresentar o valor de gasto médio para manutenção por internação muito próximo (98\%) do apresentado pelo hospital 1.

Quanto à natureza jurídica, a Figura 1 evidencia que o hospital 1 é filantrópico e os hospitais 3 e 6 são públicos, restando apenas uma questão: qual a modalidade de gestão desses hospitais públicos? São hospitais públicos administrados por Organizações Sociais de Saúde (OSS).

A fim de realizar uma rápida comparação com o que ocorre no estado de São Paulo, que adotou o modelo de gestão por OSS para seus hospitais, é interessante analisar uma informação relacionada aos gastos encontrada na pesquisa realizada por lbañez et all4. Aquele estudo teve por base dados extraídos dos relatórios produzidos pela equipe técnica responsável pelo convênio entre a SES/SP e a FSP/USP para acompanhamento do projeto.

Os autores compararam em cinco hospitais gerenciados por OSS as despesas do mês de junho de $2001 \mathrm{com}$ a receita SUS, e verificaram que os percentuais da receita SUS em relação às despesas apresentaram variação de $24 \%$ a $48 \%$ entre os hospitais. Quando os valores foram comparados com outros hospitais da administração direta, verificou-se um padrão semelhante às OSS/SUS.

No caso dos hospitais 3 e 6 , se comparados os valores do faturamento SIH/SUS com a despesa de manutenção dos hospitais no primeiro semestre de 2012, verifica-se que no hospital 3 as receitas SIH/SUS representam apenas $7 \%$, enquanto o hospital 6 apresenta resultado um pouco melhor, ou seja, $13,5 \%$ das despesas totais. Em nosso caso, não há nenhum hospital estadual sendo gerenciado atualmente pela administração direta para comparação, mas fazê-lo com os valores apresentados nos hospitais da SES/SP evidencia uma situação bastante diversa. Outro aspecto que deveria também ser considerado refere-se ao porte e à complexidade dos hospitais de São Paulo para enriquecer a comparação.

Barata e Mendes ${ }^{15}$ compararam indicadores de 13 hospitais administrados por OSS (2.998 leitos) com 13 hospitais da administração direta* (2.925 leitos) com base em dados de 2005. Os hospitais eram de porte e características de atendimento semelhante e propiciaram os dados apresentados na Tabela 2.

Tabela 2. Comparativo dos indicadores hospitalares de 26 hospitais da SES/SP, conforme modelo de gestão, dados de 2005.

\begin{tabular}{l|rrr}
\hline Descrição & Adm. direta & OSS & Diferença \\
\hline Orçamento (R\$ milhões) & 612,45 & 662,18 & $>8,1 \%$ \\
Taxa de ocupação dos hospitais & $75,8 \%$ & $79 \%$ & $>4,2 \%$ \\
Número de saídas (mil) & 116 & 166 & $>42,8 \%$ \\
Número de saídas por leito & 39,7 & 58,1 & $>46,1 \%$ \\
Gasto médio por saída $(\mathrm{R} \$)$ & $3.554,00$ & $2.691,00$ & $<24,3 \%$ \\
\hline
\end{tabular}

Fonte: Barata e Mendes ${ }^{15}$ 
Os autores comentam que com um orçamento $8 \%$ maior os hospitais gerenciados por OSS registraram um gasto médio por saída/alta do leito $24 \%$ menor.

Mesmo utilizando internações e não saídas nesta pesquisa, percebe-se que a diferença entre os valores registrados para as OSS da SES/SP é bastante inferior àquela detectada nos dois hospitais gerenciados por OSS aqui no estado de Mato Grosso. Se comparados os valores, observa-se que o gasto médio por saída das OSS da SES/SP representa somente $48 \%$ do gasto médio por internação do hospital 6 e apenas $25 \%$ do gasto médio por internação do hospital 3, diferenças significativas. Lembra-se que a inflação acumulada (IPCA) medida entre os sete anos que separam as duas pesquisas foi de $41,7 \%{ }^{16}$. Ainda que exista a limitação relacionada ao porte e à complexidade dos hospitais de São Paulo, os hospitais mato-grossenses sob gestão de OSS não são de grande porte e nem ao menos realizam grande volume de internações de alta complexidade. Caso tais características existissem, poderiam justificar tamanha diferença.

Longe de ser conclusivo quanto a esse assunto, os resultados do estado de Mato Grosso comparados aos resultados das OSS da SES/SP contribuem para a discussão relacionada à inserção de Organizações Sociais de Saúde na gestão dos hospitais públicos do estado de Mato Grosso. Ressalta-se que o objetivo principal desse trabalho não foi estudar a atuação das OSS nos hospitais da SES/MT, mas apenas comparar a qualidade e a eficiência de hospitais públicos, privados e filantrópicos, estando no âmbito destes os hospitais gerenciados por OSS. No entanto, os dados apresentados alertam para a necessidade de melhor acompanhamento da operacionalização do modelo.

Embora os dados analisados sejam de 2012, é importante ressaltar no ano de 2011, o relatório de auditoria das contas anuais de gestão do Fundo Estadual de Saúde de $2011^{17}$ apontou diversas irregularidades na contração e execução dos contratos, as quais incluem: ausência de estudos (de custos, efetividade, eficiência) que justificassem o valor dos contratos; descumprimento de diversas cláusulas contratuais pelas OSS sem a devida punição aplicada pela SES/MT; pagamento de valores indevidos, acima das estimativas previstas em contrato; recebimento pelas OSS de valores sem a devida contraprestação de serviços. Em virtude desse recebimento, no mesmo relatório o relator indica a responsabilidade e citação das OSS quanto à devolução de um total de mais de $R \$ 20.000 .000,00$ (vinte milhões de reais) em virtude de haverem recebido valores sem a contraprestação de serviços, caracterizando transferência gratuita de recursos e enriquecimento sem causa.

\section{CONSIDERAÇÕES FINAIS}

Como é possível notar, os resultados chamam a atenção para o alto valor do gasto médio por internação nos hospitais públicos sob gestão de OSS em Mato 
Grosso, os quais, aparentemente, não se justificam, principalmente quanto são analisados o porte dos hospitais e a complexidade dos procedimentos realizados.

Diante disso, conforme já apontado pelo Tribunal de Contas, fica evidente que esse processo de transferência de gestão dos hospitais públicos para as Organizações Sociais, que em Mato Grosso foi operacionalizado a toque de caixa, possivelmente em virtude dos interesses envolvidos, no entanto, o sistema de acompanhamento e normatização da transferência e aplicação dos recursos foi bastante falho. $O$ modo falho de fiscalização pode ter sido operacionalizado intencionalmente a fim de ocultar os desvios ocorridos, conforme aponta o órgão de controle.

Mesmo diante de tais fatos e outros escândalos que provocaram o encerramento de contrato com algumas OSS, ainda existem pelo menos dois dos seis hospitais estaduais sendo geridos por esse modelo.

Assim, esta pesquisa traz um alerta para a necessidade de possíveis melhorias no monitoramento e na avaliação dos contratos de gestão, estabelecendo o controle dos custos de operação dos hospitais a fim de revisar os valores dos contratos. O acompanhamento da operacionalização do modelo poderia ser supervisionado por uma equipe técnica externa, independente, composta por profissionais com expertise em gestão hospitalar. Tal medida poderia aprimorar o modelo, eliminando possíveis incoerências. Recomenda-se novos estudos com abordagem semelhante e utilizando maior abrangência amostral e temporal, a fim de possibilitar aprofundamento e ampliação das discussões sobre o tema.

\section{REFERÊNCIAS}

1. La Forgia G, Couttolenc BF. Desempenho hospitalar no Brasil: em busca da excelência. São Paulo: Singular, 2009.

2. Braga Neto FC, Barbosa PR, Santos IS. Atenção hospitalar: evolução histórica e tendências. In: Giovanella L, Escorel S, Lobato LVC et al. (Organizadores). Políticas e sistema de saúde no Brasil. Rio de Janeiro: Editora FIOCRUZ, 2008.

3. Saltaman RB. Melting public-private boundaries in European health systems. European journal of public health 2003 Mar; 13(1):24-9

4. Barbosa NB, Elias PEM. As organizações sociais de saúde como forma de gestão público/privado. Ciência \& Saúde Coletiva, 15(5):2483-2495, 2010.

5. Brasil. Ministério da Administração Federal e da Reforma do Estado. Organizações sociais. Cadernos MARE da Reforma do Estado. № . 2, 4aㅡ edição. Brasília, 1998. 
6. Pahim MLL. Organizações Sociais de Saúde no estado de São Paulo: inserção privada no SUS e gestão financeira do modelo pela Secretaria de Estado de Saúde. [Tese de doutorado]. Faculdade de Medicina. Universidade de São Paulo. São Paulo, 2009.

7. Meireles HL. Direito Administrativo Brasileiro. 32a․ Edição. São Paulo: Malheiros Editores, 2007.

8. Mello CAB. Curso de direito administrativo. 21ㄹ. Edição. São Paulo: Malheiros Editores, 2007.

9. Di Pietro MSZ. Direito Administrativo. São Paulo: Atlas, 2007.

10. Ibañez N, Veciana Neto G. Modelos de gestão e o SUS. Ciência \& Saúde Coletiva, 12(Sup):1831-1840, 2007

11. Botti CS. Avaliação do processo de implementação do Consórcio Intermunicipal de Saúde da região do Teles Pires [dissertação de mestrado]. Brasília: FIOCRUZ Fundação Oswaldo Cruz, Escola Nacional de Saúde Pública Sergio Arouca, 2011.

12. Ministério da Saúde. Secretaria de Atenção à Saúde. DATASUS. Sistema de Informações Hospitalares - SIHSUS Reduzida. Brasília, 2012. [acesso dia 20 de março de 2013]. Disponível: em: http://www2.datasus.gov.br/DATASUS/index.php?area=0701\&item=1\&acao $=11$

13. Ministério da Saúde. Glossário do Ministério da Saúde: projeto de terminologia em saúde. Brasília, MS, 2004.

14. Ibañez N, Bittar OJNV, Sá ENC, Yamamoto EK, Almeida MF, Castro CGJ. Organizações Sociais de Saúde: o modelo do estado de São Paulo. Ciência \& Saúde Coletiva, 6(2):391-404, 2001.

15. Barata LRB, Mendes JDV. Organizações Sociais de Saúde: a Experiência Exitosa de Gestão Pública de Saúde do Estado de São Paulo. In: BRASIL. Conselho Nacional de Secretários de Saúde. Progestores - Nota Técnica 17/2006. Brasília: CONASS, 2006.

16. Bacen. Banco Central do Brasil. Histórico de metas para inflação no Brasil. Acesso dia 25 de março de 2014. Disponível em: http://www.bcb.gov.br/Pec/metas/TabelaMetaseResultados.pdf

17. Tribunal de Contas do Estado de Mato Grosso. Secretaria de Controle Externo. Conselheiro Humberto Bosaipo. Relatório de Auditoria. Contas anuais de gestão - 2011; Fundo Estadual de Saúde do Estado de Mato Grosso. Folhas 6032- 6414. Mato Grosso, 2011.

18. Ministério da Saúde. Secretaria de Atenção à Saúde. DATASUS. Cadastro Nacional de Estabelecimentos de Saúde - CNES. Brasília, 2012a. [acesso dia 20 de junho de 2012]. Disponível em: http://tabnet.datasus.gov.br/cgi/deftohtm.exe?cnes/cnv/estabmt.def 
19. FERREIRA, M. P. Assistência à saúde nos Departamentos Regionais de Saúde: um exercício metodológico sobre eficiência e acesso aos serviços de saúde. [Tese de doutorado]. Faculdade de Medicina. Universidade de São Paulo. São Paulo, 2009.

Recebido: 16 de janeiro de 2018. Publicado: 14 de março de 2018

Correspondência: Paulo Cesar Souza. E-mail: paulobbg@unemat.br

Conflito de Interesses: os autores declararam não haver conflito de interesses.

(C) This is an Open Access article distributed under the terms of the Creative Commons Attribution License, which permits unrestricted use, distribution, and reproduction in any medium, provided the original work is properly cited 